\title{
Inpatient Hyperglycemia Management and COVID-19
}

Virginia Bellido (D) · Antonio Pérez

Received: September 10, 2020 / Accepted: November 3, 2020 / Published online: December 5, 2020

(C) The Author(s) 2020

\section{ABSTRACT}

Diabetes is one of the most common comorbidities in hospitalized patients with coronavirus disease 2019 (COVID-19). Inpatient hyperglycemia during this pandemic has been associated with worse outcomes, so it is mandatory to implement effective glycemic control treatment approaches for inpatients

V. Bellido

Department of Endocrinology and Nutrition, Cruces University Hospital, Vizcaya, Spain

V. Bellido

Biocruces Bizkaia Health Research Institute, Vizcaya, Spain

V. Bellido

University of the Basque Country (UPV/EHU),

Vizcaya, Spain

A. Pérez (訩

Department of Endocrinology and Nutrition, Santa Creu I Sant Pau Hospital, Barcelona, Spain

e-mail: aperez@santpau.cat

A. Pérez

Sant Pau Institute of Biomedical Research, Barcelona, Spain

A. Pérez

Autonomous University of Barcelona, Barcelona, Spain

\section{A. Pérez}

CIBER de Diabetes Y Enfermedades Metabólicas

Asociadas (CIBERDEM), Barcelona, Spain with COVID-19. The shortage of personal protective equipment, the need to prevent staff exposure, or the fact that many of the healthcare professionals might be relatively unfamiliar with the management of hyperglycemia may lead to worse glycemic control and, consequently, a worse prognosis. In order to reduce these barriers, we intend to adapt established recommendations to manage hyperglycemia during this pandemic in critical and noncritical care settings.

Keywords: COVID-19; Diabetes; Hospitalized; Hyperglycemia; Inpatient; Insulin therapy; SARS-CoV-2 


\section{Key Summary Points}

Diabetes is one of the most common comorbidities in hospitalized patients with coronavirus disease 2019 (COVID19).

Inpatient hyperglycemia during the COVID-19 pandemic has been associated with worse outcomes, but improvement of glycemic control can reduce complications associated with hyperglycemia.

Effective glycemic control treatment approaches for inpatients with COVID-19 are needed while, at the same time, limiting the exposure of healthcare professionals. An individualized approach adapting the established recommendations for the management of hyperglycemia in hospitalized patients may reduce the barriers during COVID-19 pandemic.

\section{DIGITAL FEATURES}

This article is published with digital features, including a summary slide, to facilitate understanding of the article. To view digital features for this article go to https://doi.org/10.6084/ m9.figshare.13182836.

\section{INTRODUCTION}

Diabetes is one of the most common comorbidities of coronavirus disease 2019 (COVID$19)$, caused by severe acute respiratory syndrome coronavirus 2 (SARS-CoV-2) infection. The prevalence of diabetes among people affected by COVID-19 is not higher than that observed in the general population, suggesting that diabetes does not increase the risk of SARSCoV-2 infection, but can worsen the outcome of the disease $[1,2]$. In fact, clinical studies have found diabetes to be a major risk factor for disease severity and mortality $[3,4]$. Patients with diabetes and/or uncontrolled hyperglycemia are more than twice as likely to be admitted to intensive care units (ICU) and mortality is up to three times higher compared to patients without diabetes and/or uncontrolled hyperglycemia [5].

It is well established that inpatient hyperglycemia, with or without known diabetes, contributes to a significant increase in morbidity, mortality, length of hospital stay, and healthcare costs, and that better glycemic control improves clinical outcomes [6-8]. This was also evident in prior coronavirus infection outbreaks like the severe acute respiratory syndrome (SARS) [9].

Several mechanisms have linked hyperglycemia to the worse prognosis of COVID-19. These mechanisms include those related to hyperglycemia and glycemic control as well as the impaired immune and inflammatory response caused by hyperglycemia [10]. Poor glycemic control has been associated with worse outcomes, including higher resource utilization, prolonged length of hospitalization, multi-organ injuries, and higher mortality [10-13]. Hyperglycemia in patients with and without diabetes can also have a negative impact on the efficacy of COVID-19 therapies, such as tocilizumab [14]. Frequent comorbidities associated with diabetes, such as obesity and hypertension, have also been associated with poor prognosis [15]. However, a recent study has shown that diabetes is associated with poor early outcomes among hospitalized patients with COVID-19, after adjustment for obesity [16]. In addition, accelerated respiratory deterioration has recently been identified as another mechanism whereby hyperglycemia can lead to worse outcomes of COVID-19 [17].

While some of these mechanisms remain to be elucidated, it seems clear that optimizing glycemic control can be crucial to improve COVID-19 outcomes. Well-controlled blood glucose (BG) levels, defined as BG between 70 and $180 \mathrm{mg} / \mathrm{dL}(3.9$ and $10.0 \mathrm{mmol} / \mathrm{L})$ have been associated with reduced medical interventions, major organ injuries, and all-cause mortality [11]. In fact, for every $10 \mathrm{mg} / \mathrm{dL}$ 
$(0.6 \mathrm{mmol} / \mathrm{L})$ drop in glucose levels between admission and 18 days, an $11 \%$ relative decrease in severe disease risk has been described in patients with hyperglycemia [10].

The limited data available suggest that glycemic control in patients with COVID-19 is inadequate. An observational study that evaluated glycemic control among hospitalized patients with COVID-19, diabetes, and acute hyperglycemia described $39.1 \%$ of BG values above $180 \mathrm{mg} / \mathrm{dL}(10.0 \mathrm{mmol} / \mathrm{L})$ and $37.8 \%$ of the time of admission spent with a mean BG above $180 \mathrm{mg} / \mathrm{dL}$ (10.0 mmol/L) [12]. Another study showed $56.6 \%$ of capillary BG tests above the recommended target of $140-180 \mathrm{mg} / \mathrm{dL}$ $(7.8-10.0 \mathrm{mmol} / \mathrm{L})$ [18]. This may be due to high levels of stress, inflammation, a cytokinemediated insulin-resistant state and lack of adequate protocols for glucose management [19]. It is also possible that the SARS coronavirus can penetrate into pancreatic islets and damage beta cells leading to insulin deficiency, thereby aggravating the course of diabetes and triggering acute hyperglycemia even in people without diabetes $[20,21]$. This is supported by the observation of frequent cases of ketosis and severe diabetic ketoacidosis (DKA) at the time of hospital admission [22]. On the other hand, a rather large number or hypoglycemic episodes at hospital admission have also been reported, probably favored by COVID-19-induced anorexia without concomitant adaptation of glucose-lowering drugs $[18,20]$. There are other factors associated with BG fluctuation that are especially relevant in patients with diabetes and COVID-19, such as the use of glucocorticoids, that can lead to large glycemic excursions which should be considered in setting the insulin pattern [23].

In addition, healthcare workers can face challenges that need careful attention. Specialists from all disciplines may have to manage patients with COVID-19 outside of their usual specialty areas and, therefore, clinicians relatively unfamiliar with managing hyperglycemia may be required to do so [24]. The shortage of personal protective equipment and the need to prevent healthcare workers' exposure can also hinder glycemic control in patients with COVID-19.
In this clinical scenario, there is an urgent need to implement effective glycemic control treatment approaches for inpatients with COVID-19 [25]. However, no data is available regarding the most appropriate management of hyperglycemia in patients infected by SARSCoV-2. Until then, given the aforementioned challenges, we intend to adapt established recommendations to manage hyperglycemia during this pandemic in critical and noncritical care settings. In Table 1 we summarize the main recommendations for the management of hyperglycemia in critically ill and noncritically ill patients with COVID-19 according to their clinical situation. This article is based on previously conducted studies and does not contain any studies with human participants or animals performed by any of the authors.

\section{MANAGEMENT OF HYPERGLYCEMIA IN CRITICAL PATIENTS WITH COVID-19}

\section{Glycemic Targets}

Glycemic control goals in the ICU have been the subject of debate during the past 2 decades. It is generally accepted that intensive glycemic control [80-110 mg/dL (4.4-6.1 mmol/L)] compared to moderate control [140-180 mg/dL (7.8-10.0 mmol/L)] does not provide any benefit and in fact can increase the risk of hypoglycemia and even mortality $[26,27]$. There is agreement that glucose levels above $180 \mathrm{mg} / \mathrm{dL}$ $(10.0 \mathrm{mmol} / \mathrm{L})$ may increase the risk of hospital complications. However, the lower limit for glycemia target is less well established and values greater than $110 \mathrm{mg} / \mathrm{dL}(6.1 \mathrm{mmol} / \mathrm{L})$ are generally recommended in order to minimize the risks of hypoglycemia [7]. The GLUCOCABG study showed a significant reduction in complications among patients undergoing coronary artery bypass graft surgery without diabetes comparing a glucose target of $100-140 \mathrm{mg} / \mathrm{dL}(5.6-7.8 \mathrm{mmol} / \mathrm{L})$ to a target of 141-180 mg/dL (7.8-10.0 mmol/L) [28], and the results of Krinsley et al.'s study in critically ill patients support a BG target of $80-140 \mathrm{mg} / \mathrm{dL}$ 
Table 1 Hyperglycemia management in critically and noncritically ill patients with COVID-19

\begin{tabular}{|c|c|c|c|c|c|}
\hline & Glycemic targets & \multicolumn{2}{|c|}{ Clinical situation } & Insulin regimen & BG monitoring \\
\hline \multirow[t]{2}{*}{$\begin{array}{l}\text { Critically ill } \\
\text { patients }\end{array}$} & \multirow[t]{2}{*}{$\begin{array}{l}140-180 \mathrm{mg} / \mathrm{dL}^{*} \\
(7.8-10.0 \mathrm{mmol} / \\
\mathrm{L})\end{array}$} & \multicolumn{2}{|c|}{$\begin{array}{l}\text { Hemodynamically unstable } \\
\text { Parenteral nutrition } \\
\text { Unstable insulin requirements }\end{array}$} & $\begin{array}{l}\text { Continuous } \\
\text { intravenous insulin } \\
\text { infusion }\end{array}$ & Every hour \\
\hline & & \multicolumn{2}{|c|}{$\begin{array}{l}\text { Hemodynamically stable } \\
\text { Stable insulin requirements }\end{array}$} & $\begin{array}{l}\text { Subcutaneous insulin } \\
\text { Basal-correction or } \\
\text { basal-bolus- } \\
\text { correction }\end{array}$ & Every $4-6$ h \\
\hline \multirow[t]{3}{*}{$\begin{array}{r}\text { Noncritically } \\
\text { ill patients }\end{array}$} & \multirow[t]{3}{*}{$\begin{array}{l}110-180 \mathrm{mg} / \mathrm{dL}^{* *} \\
\quad(6.1-10.0 \mathrm{mmol} / \\
\mathrm{L})\end{array}$} & $\begin{array}{l}\text { T1D } \\
\text { T2D on } \\
\text { oral } \\
\text { agents } \\
\pm \text { insulin }\end{array}$ & $\begin{array}{l}\text { Not oral intake } \\
\text { Oral intake }\end{array}$ & $\begin{array}{l}\text { Basal-correction } \\
\text { Basal-bolus- } \\
\text { correction }\end{array}$ & $\begin{array}{l}\text { Every } 4-6 h^{\# \#} \\
\text { Before meals and at } \\
\text { bedtime }\end{array}$ \\
\hline & & $\begin{array}{l}\text { T2D on } \\
\text { diet } \\
\text { Unknown }\end{array}$ & $\begin{array}{l}\text { Glycemia at admission } \\
<180 \mathrm{mg} / \mathrm{dL} \\
(10.0 \mathrm{mmol} / \mathrm{L})\end{array}$ & $\begin{array}{l}\text { Correction insulin } \\
\text { before meals or } \\
\text { every } 6 \mathrm{~h}^{\#}\end{array}$ & $\begin{array}{l}\text { Before meals and at } \\
\text { bedtime or every } \\
6 \mathrm{~h}^{\# \#}\end{array}$ \\
\hline & & DM & $\begin{array}{l}\text { Glycemia at admission } \\
>180 \mathrm{mg} / \mathrm{dL} \\
(10.0 \mathrm{mmol} / \mathrm{L})\end{array}$ & $\begin{array}{l}\text { Basal-bolus- } \\
\text { correction }\end{array}$ & $\begin{array}{l}\text { Before meals and at } \\
\text { bedtime }^{\# \#}\end{array}$ \\
\hline
\end{tabular}

$B G$ blood glucose, $T 1 D$ type 1 diabetes, $T 2 D$ type 2 diabetes, $D M$ diabetes mellitus

${ }^{*} 110-140 \mathrm{mg} / \mathrm{dL}(6.1-7.8 \mathrm{mmol} / \mathrm{L})$ may be reasonable for selected patients, as long as it can be achieved without significant hypoglycemia

${ }^{* *} 110-140 \mathrm{mg} / \mathrm{dL}(6.1-7.8 \mathrm{mmol} / \mathrm{L})$ may be reasonable for stable patients with mild disease and previous tight glycemic control. BG levels $>180 \mathrm{mg} / \mathrm{dL}(7.8 \mathrm{mmol} / \mathrm{L})$ might be acceptable for patients who are at high risk of hypoglycemia or who have limited life expectancy

\# To calculate insulin requirements during the first $24 \mathrm{~h}$. Then intensify to a basal-correction or basal-bolus regimen

\#\# Consider the use of continuous glucose monitoring if feasible to limit fingersticks

(4.4-7.8 $\mathrm{mmol} / \mathrm{L})$ for patients without diabetes and with diabetes when HbA1c is less than 7\% (53 mmol/mol), but $110-160 \mathrm{mg} / \mathrm{dL} \quad$ (6.1$8.9 \mathrm{mmol} / \mathrm{L}$ ) in those with HbA1c levels of at least $7 \%(53 \mathrm{mmol} / \mathrm{mol})$ [29]. Also deserving attention is the fact that glycemic variability per se has been associated with higher mortality rates than hyperglycemia in septic patients [30]. It has therefore been suggested that glycemic variability has to be part of the management of hyperglycemia, even in ICU patients [31]. These data, like those established for outpatient diabetes management, support a potential benefit of a personalized glycemic target in critically ill patients.

Clinical guidelines recommend maintaining glucose levels between 140 and $180 \mathrm{mg} / \mathrm{dL}$ (7.8-10.0 mmol/L) for most critically ill patients [32] and more stringent goals of $110-140 \mathrm{mg} / \mathrm{dl}$ (6.1-7.8 $\mathrm{mmol} / \mathrm{L})$ may be reasonable for selected patients, as long as they can be achieved without significant hypoglycemia [7, 28, 29]. In 
accordance with Pasquel et al. [33], we consider that these recommendations could be extended to critical patients with COVID-19.

\section{Insulin Therapy}

Insulin should be the treatment of choice for critically ill patients with COVID-19. The main aims of a safe and effective insulin regimen should be to reduce contact frequency, reduce glucose variability, minimize risk of severe hypoglycemia, and improve overall glycemic control [34]. As a result of the stress caused by SARS-CoV-2 infection and other factors, such as continuous tube feeding in patients on artificial ventilation and the risk of hypoglycemia when tube feeding is interrupted, or the use of high doses of corticosteroids, patients may suffer from great glycemic excursions [34]. To achieve glycemic targets, continuous intravenous insulin infusion, based on validated written or computerized protocols, is the most effective method $[7,35,36]$. The protocols that do not need a calculation of insulin doses (printed with decision columns and computerized protocols) are preferable to those that require calculations to decide the dose. Training of physicians and especially nurses in the efficient use of the protocol as well as predefining adjustments before important changes in BG and/or situations in which corticosteroids, vasopressors, parenteral nutrition, etc., are removed or added is important for protocol safety. However, the main factor that contributes to the safety of the protocol is the frequency of glycemic monitoring. The majority of insulin infusion protocols demand a minimum of hourly glucose monitoring for successful glycemic target achievement while reducing the risk of hypoglycemia. Checking glucose levels with a meter and test strips requires caregivers to enter a patient's room. In order to minimize healthcare workers' exposure when managing hyperglycemia in critically ill patients with COVID-19, for hemodynamically stable patients who are not on parenteral nutrition or high-dose corticosteroids, we recommend that the use of subcutaneous basal-bolus-correction or basalcorrection insulin regimens should be considered instead of intravenous insulin infusion and check BG levels four times a day together with other nursing activities to reduce the need to enter a patient's room. Transfer from intravenous to subcutaneous insulin administration will be recommended when the patient is clinically stable $[37,38]$. The initial dose of subcutaneous insulin administration at the time of transition can be determined as $60-80 \%$ of the insulin administered intravenously during the preceding $24 \mathrm{~h}$. To avoid rebound hyperglycemia after transition, a sufficient duration of overlap with the insulin infusion and the subcutaneous insulin administration is required. Short-acting insulin can be administered 1 to $2 \mathrm{~h}$ and long-acting insulin 2 to $3 \mathrm{~h}$ prior to discontinuation of intravenous insulin administration.

\section{MANAGEMENT OF HYPERGLYCEMIA IN NONCRITICAL PATIENTS WITH COVID-19}

\section{Glycemic Targets}

The American Diabetes Association (ADA) proposes the range of $140-180 \mathrm{mg} / \mathrm{dL} \quad(7.8-$ $10.0 \mathrm{mmol} / \mathrm{L}$ ) as a target level of $\mathrm{BG}$ for the majority of noncritically ill patients [39]. However, the ideal glucose goals for noncritically ill patients remain undefined, and current recommendations are based mostly on retrospective studies, clinical experience, and judgment [7].

Evidence regarding appropriate glycemic targets for hospitalized patients with COVID-19 is lacking. As mentioned before, BG levels maintained between 70 and $180 \mathrm{mg} / \mathrm{dL}$ (3.9 and $10.0 \mathrm{mmol} / \mathrm{L}$ ) have been associated with better clinical outcomes [11]. Premeal and fasting BG values below $140 \mathrm{mg} / \mathrm{dL} \quad(7.8 \mathrm{mmol} / \mathrm{L})$ with maximal random BG below $180 \mathrm{mg} / \mathrm{dL}$ $(10.0 \mathrm{mmol} / \mathrm{L})$ might be appropriate in stable patients with mild disease and previous tight glycemic control, while glucose levels above $180 \mathrm{mg} / \mathrm{dL} \quad(10.0 \mathrm{mmol} / \mathrm{L})$ might be acceptable in patients who are at high risk of hypoglycemia or who have limited life 
expectancy, as a way of minimizing the risk of hypoglycemia [7].

\section{Insulin Therapy}

There are limited data available about the efficacy and safety of non-insulin agents in hospitalized patients, almost restricted to dipeptidyl peptidase 4 (DPP4) inhibitors [40-44]. These agents in combination with basal insulin may represent an alternative in patients with COVID-19 and mild to moderate hyperglycemia [33]. DPP4 inhibitors have also been suggested to have a protective effect on COVID-19 [45]. However, recent studies found no association between the use of DPP4 inhibitors before admission and COVID-19 prognosis [20, 46, 47]. Moreover, we still do not have data on their use in hospitalized patients with COVID-19, and they may not be available in many hospitals. The incorporation of non-insulin drugs expands the therapeutic options and consequently the complexity of the prescription, which can be especially difficult when clinicians are unfamiliar with managing hyperglycemia. Glucagon-like peptide 1 (GLP-1) receptor agonists could be an attractive option, but they may increase the risk of gastrointestinal side effects [48]. Metformin and sodium-glucose cotransporter 2 (SGTL2) inhibitors should be discontinued at admission, because of the risk of lactic acidosis and DKA, respectively [49]. Some authors hypothesized that SGLT2 inhibitors could be effective in patients with hypoxemia and interstitial lung edema due to SARS-CoV-2 infection [50, 51]. Experience with three hospitalized patients without diabetes has been reported, showing no beneficial effects with the use of SGLT2 inhibitors [50]. All other oral agents, such as sulfonylureas or thiazolidinediones, should also be discontinued at admission.

Insulin is still considered the most appropriate pharmacologic agent for effectively controlling glycemia in hospital. Several regimens have proven to be effective for achieving and maintaining glycemic control. Current clinical guidelines recommend basal-bolus insulin regimens as the standard care for hospitalized patients with hyperglycemia and diabetes in noncritical care setting [32,36]. There is no data regarding the most appropriate regimen for patients with COVID-19, but the importance of achieving good glycemic control is evident [10].

A lot of evidence supports the use of basalbolus regimens in noncritically ill patients. Randomized clinical trials have shown that basal-bolus treatment improves glycemic control and reduces the rate of hospital complications compared with reactive, or sliding-scale, insulin regimens $[8,52]$. Compared to premixed insulin (70/30 NPH/regular insulin), a basalbolus regimen has shown comparable glycemic control, but significantly fewer hypoglycemic episodes in medical and surgical patients [53]. A basal plus regimen compared with a standard basal-bolus regimen in medical and surgical patients with type 2 diabetes treated with diet, oral antidiabetic agents, or low-dose insulin resulted in a similar improvement in glycemic control without differences in hypoglycemia [54]. As for the types of insulin, regimens using insulin analogues and human insulin result in similar glycemic control in the hospital setting [55]. However, NPH insulin-based basal-bolus regimens have been largely supplanted by insulins analogue because of a perceived lower risk of hypoglycemia and because NPH insulin usually cannot be administered once daily. There are limited data regarding the use of new basal insulin analogues in the hospital setting. A recent study comparing glargine U300 and glargine U100 in a basal-bolus regimen in general medical and surgical patients with type 2 diabetes resulted in similar glycemic control, but significantly lower rates of clinically significant hypoglycemia [BG below $54 \mathrm{mg} / \mathrm{dL}$ (3 mmol/L)] with the use of glargine U300 [56]. In line with this study, another recent study in people with type 2 diabetes insufficiently controlled with basal insulin and/or non-insulin antidiabetic drugs, the COBALTA trial, confirms the efficacy and safety of insulin glargine U300 during hospitalization. This study also demonstrates that therapy intensification at discharge with glargine U300 is an effective strategy, improving HbA1c by $1.6 \%$ at months 3 and 6 post discharge with an adequate safety profile and a high degree of treatment satisfaction [57]. 
On the basis of these results, an insulin regimen with basal, prandial, and correction components would be the preferred treatment for noncritically ill hospitalized patients with COVID-19 and good nutritional intake, and basal insulin or a basal plus correction for patients with poor oral intake or those in which oral intake cannot be ensured [32]. Prolonged use of sliding-scale insulin regimens as the sole treatment of hyperglycemia is strongly discouraged [32].

\section{Insulin Therapy in Glucocorticoid- Induced Hyperglycemia}

The use of glucocorticoid therapy can aggravate or precipitate hyperglycemia in hospitalized patients with COVID-19 with and without known diabetes [58]. Regarding the use of high doses of corticosteroids in these patients, some authors have described their experience adding $\mathrm{NPH}$ insulin in a dose of 20-30 units in the morning in addition to the current insulin regimen as an efficient strategy to minimize the impact of steroids on BG values [34]. In our experience, the best option is to add the calculated increase in insulin dose, considering body weight and glucocorticoid dose, to the patient's usual total dose, distributing it according to the usual insulin regimen and glucocorticoid schedule [23].

\section{GLUCOSE MONITORING IN HOSPITAL IN PATIENTS WITH COVID-19}

Maintaining an adequate glycemic control usually requires multiple daily glucose measurements, which can be a challenge in patients under strict isolation. The implementation of technology that minimizes staff exposure while maintaining standard of care for hospitalized patients with diabetes is essential [59].

The US Food and Drug Administration (FDA) recognizes that home-use BG meters may be used by patients with diabetes who are hospitalized because of COVID-19 to check their own BG levels and provide the readings to the healthcare workers caring for them [60]. Nevertheless, a way to monitor BG remotely, from outside the isolated rooms, is required [59]. This could be achieved by using BG meters that transmit the data via Bluetooth to an app or to a cloud. However, the use of continuous glucose monitoring (CGM) might be the ideal way to monitor BG in patients with COVID-19. It would allow, on the one hand, remote monitoring; on the other hand, it would help to enable BG control with low variability in the intended target range [31].

Inpatient clinical trials have tested the accuracy, safety, and efficacy of CGM technology in hospital, in both critical and noncritical patients [61-63]. Some experiences have already been reported in noncritical patients with COVID-19 with type 1 and type 2 diabetes, with the use of Guardian Connect (Medtronic), with significant improvement in mean glucose levels in all patients [59]. The main challenges for the use of CGM in hospital include training healthcare workers, the need for calibration procedures with some CGM systems, and cost. There are some systems such as FreeStyle Libre or Dexcom G6 that do not require BG calibration, minimizing risk of staff exposure and burden. Recently, the FDA approved the use of both FreeStyle Libre and Dexcom for inpatient use during the COVID-19 healthcare crisis in noncritically ill patients, but not in the critically ill [64-66]. Both systems can securely transmit glucose measurement data to digitally connected devices. As far as we know, no experiences have been reported with the use of these two CGM systems in hospitalized patients with COVID-19.

Some issues should be taken into account with the use of CGM systems in patients with COVID-19. Hypoxemia and possible reduction in peripheral perfusion could interfere with the accuracy of interstitial glucose measurement, especially in critically ill patients [67]. Acetaminophen, a commonly used antipyretic in patients with COVID-19, can interfere with CGM readings in some systems and may cause a CGM to overestimate glucose [68] (not in FreeStyle Libre or Dexcom G6). Glucose values in patients wearing a device that may be impacted 
by acetaminophen should be interpreted with caution.

Regarding ICU patients, the integration of computer-guided insulin infusion with CGM or further development of new automated insulin delivery systems may be ideal [33]. Data about the use of hybrid closed-loop insulin infusion systems in critically ill patients are scarce. However, two recent cases of type 1 diabetes in patients with COVID-19 using t:slim Control IQ hybrid closed-loop system have been described, with optimal glycemic levels and minimal variability [34]. However, we will have to wait for more data on its efficacy and safety in critically ill patients before we can recommend its use.

Both the use of CGM systems and the use of hybrid closed-loop insulin infusion systems would require specific protocols for guidance, as well as access to specialist care [69]. Having an endocrinologist on consult, even over the phone or virtually, could help with all the approaches proposed [19, 70].

\section{CONCLUSIONS}

Improvement of glycemic control can reduce complications associated with hyperglycemia in hospitalized patients infected by SARS-CoV-2. Effective glycemic control treatment approaches for inpatients with COVID-19 are needed while, at the same time, limiting the exposure of healthcare professionals. Although we do not yet have data regarding the optimal glycemic targets for inpatients with COVID-19, it is clear that extremes of BG can lead to poor outcomes, and that insulin is the most appropriate treatment for effectively controlling glycemia in hospital. A target glucose range of $110-180 \mathrm{mg} /$ $\mathrm{dL}(6.1-10.0 \mathrm{mmol} / \mathrm{L})$ may be appropriate for most critically and noncritically ill patients, individualized according to patient characteristics and clinical situation. A continuous intravenous insulin infusion and scheduled basalbolus correction insulin are the preferred regimens for glycemic control in critically and noncritically ill hospitalized patients, respectively. An individualized approach adapting the established recommendations may reduce the aforementioned barriers during the COVID-19 pandemic. The use of subcutaneous insulin regimens in clinically stable patients may facilitate the reduction of the number of BG controls and, therefore, the exposure of the staff. In the same way, the implementation of technology that allows BG remote monitoring could help to limit fingersticks to check BG and, consequently, minimize staff exposure. The FDA approved the use of both FreeStyle Libre and Dexcom for inpatient use during the COVID-19 healthcare crisis. Further research regarding the evaluation of these changes in care is warranted in order to adapt our protocols.

\section{ACKNOWLEDGEMENTS}

Funding. Support from Sanofi was received for the development of the manuscript and funding the journal's Rapid Service Fee, but the opinions represent those of authors and not Sanofi.

Authorship. All named authors meet the International Committee of Medical Journal Editors (ICMJE) criteria for authorship for this article, take responsibility for the integrity of the work, and have given their approval for this version to be published.

Disclosures. Virginia Bellido has served as a consultant for or received research support, lecture fees or travel reimbursement from Abbott, Sanofi Aventis, Novo Nordisk, Eli Lilly, MSD, Boehringer Ingelheim, Esteve, Novartis, and Astra Zeneca.

Antonio Pérez has served as a consultant for or received research support, lecture fees or travel reimbursement from Sanofi Aventis, Almirall, Novo Nordisk, Eli Lilly, MSD, Boehringer Ingelheim, Esteve, Gilead, Novartis, Amgen, Menarini, and Astra Zeneca.

Compliance with Ethics Guidelines. This article is based on previously conducted studies and does not contain any studies with human 
participants or animals performed by any of the authors.

Data Availability. Data sharing is not applicable to this article as no datasets were generated or analyzed during the current study.

Open Access. This article is licensed under a Creative Commons Attribution-NonCommercial 4.0 International License, which permits any non-commercial use, sharing, adaptation, distribution and reproduction in any medium or format, as long as you give appropriate credit to the original author(s) and the source, provide a link to the Creative Commons licence, and indicate if changes were made. The images or other third party material in this article are included in the article's Creative Commons licence, unless indicated otherwise in a credit line to the material. If material is not included in the article's Creative Commons licence and your intended use is not permitted by statutory regulation or exceeds the permitted use, you will need to obtain permission directly from the copyright holder. To view a copy of this licence, visit http://creativecommons.org/licenses/by$\mathrm{nc} / 4.0 /$.

\section{REFERENCES}

1. Fadini GP, Morieri ML, Longato E, Avogaro A. Prevalence and impact of diabetes among people infected with SARS-CoV-2. J Endocrinol Invest. 2020;43(6):867-9.

2. Pugliese G, Vitale M, Resi V, Orsi E. Is diabetes mellitus a risk factor for COronaVIrus Disease 19 (COVID-19)? Acta Diabetol. 2020;57(11):1275-85.

3. Roncon L, Zuin M, Rigatelli G, Zuliani G. Diabetic patients with COVID-19 infection are at higher risk of ICU admission and poor short-term outcome. J Clin Virol. 2020;127:104354.

4. Zhang Y, Cui Y, Shen M, et al. Association of diabetes mellitus with disease severity and prognosis in COVID-19: a retrospective cohort study. Diabetes Res Clin Pract. 2020;108227.

5. Singh AK, Gupta R, Ghosh A, Misra A. Diabetes in COVID-19: prevalence, pathophysiology, prognosis and practical considerations. Diabetes Metab Syndr. 2020;14:303-10.

6. Umpierrez GE, Isaacs SD, Bazargan N, You X, Thaler LM, Kitabchi AE. Hyperglycemia: an independent marker of in-hospital mortality in patients with undiagnosed diabetes. J Clin Endocrinol Metab. 2002;87:978-82.

7. Pérez A, Ramos A, Carreras G. Insulin therapy in hospitalized patients. Am J Ther. 2020;27:e71-8.

8. Umpierrez GE, Smiley D, Jacobs S, et al. Randomized study of basal-bolus insulin therapy in the inpatient management of patients with type 2 diabetes undergoing general surgery (RABBIT 2 surgery). Diabetes Care. 2011;34:256-61.

9. Yang JK, Feng Y, Yuan MY, et al. Plasma glucose levels and diabetes are independent predictors for mortality and morbidity in patients with SARS. Diabet Med. 2006;23:623-8.

10. Sardu C, D'Onofrio N, Balestrieri ML, et al. Outcomes in patients with hyperglycemia affected by Covid-19: can we do more on glycemic control? Diabetes Care. 2020;43(7):1408-15.

11. Zhu L, She Z-G, Cheng X, et al. Association of blood glucose control and outcomes in patients with COVID-19 and pre-existing type 2 diabetes. Cell Metab. 2020;31(6):1068-77.e3.

12. Bode B, Garrett V, Messler J, et al. Glycemic characteristics and clinical outcomes of COVID-19 patients hospitalized in the United States. J Diabetes Sci Technol. 2020;14(4):813-21.

13. Yan Y, Yang Y, Wang F, et al. Clinical characteristics and outcomes of patients with severe covid-19 with diabetes. BMJ Open Diabetes Res Care. 2020;8: e001343.

14. Marfella R, Paolisso P, Sardu C, et al. Negative impact of hyperglycaemia on tocilizumab therapy in Covid-19 patients. Diabetes Metab. 2020;46(5): 403-5.

15. Zhou Y, Chi J, Lv W, Wang Y. Obesity and diabetes as high-risk factors for severe coronavirus disease 2019 (Covid-19). Diabetes Metab Res Rev. 2020. https://doi.org/10.1002/dmrr.3377.

16. Seiglie J, Platt J, Cromer SJ, et al. Diabetes as a risk factor for poor early outcomes in patients hospitalized with COVID-19. Diabetes Care. 2020;dc201506.

17. Fadini GP, Morieri ML, Boscari F, et al. Newly-diagnosed diabetes and admission hyperglycemia predict COVID-19 severity by aggravating 
respiratory deterioration. Diabetes Res Clin Pract. 2020;168:108374.

18. Zhou J, Tan J. Diabetes patients with COVID-19 need better blood glucose management in Wuhan, China. Metabolism. 2020;107:154216.

19. Al-Jaghbeer MJ, Lansang MC. Hyperglycemia management in the critically ill patient with COVID-19. Cleve Clin J Med. 2020. https://doi.org/10.3949/ ccjm.87a.ccc012.

20. Scheen AJ, Marre M, Thivolet C. Prognostic factors in patients with diabetes hospitalized for COVID19: findings from the CORONADO study and other recent reports. Diabetes Metab. 2020;46(4):265-71.

21. Yang J-K, Lin S-S, Ji X-J, Guo L-M. Binding of SARS coronavirus to its receptor damages islets and causes acute diabetes. Acta Diabetol. 2010;47:193-9.

22. Li J, Wang X, Chen J, Zuo X, Zhang H, Deng A. COVID-19 infection may cause ketosis and ketoacidosis. Diabetes Obes Metab. 2020. https:// doi.org/10.1111/dom.14057.

23. Perez A, Jansen-Chaparro S, Saigi I, Bernal-Lopez MR, Miñambres I, Gomez-Huelgas R. Glucocorticoid-induced hyperglycemia. J Diabetes. 2014;6: 9-20.

24. Rayman G, Lumb A, Kennon B, et al. New guidance on managing inpatient hyperglycaemia during the COVID-19 pandemic. Diabet Med. 2020;37(7): 1210-3.

25. Wang A, Zhao W, Xu Z, Gu J. Timely blood glucose management for the outbreak of 2019 novel coronavirus disease (COVID-19) is urgently needed. Diabetes Res Clin Pract. 2020;162:108118.

26. NICE-SUGAR Study Investigators, Finfer S, Chittock $\mathrm{DR}$, et al. Intensive versus conventional glucose control in critically ill patients. $\mathrm{N}$ Engl J Med. 2009;360:1283-97.

27. Van den Berghe $G$, Wilmer $A$, et al. Intensive insulin therapy in the medical ICU. N Engl J Med. 2006;354:449-61.

28. Umpierrez G, Cardona S, Pasquel F, et al. Randomized controlled trial of intensive versus conservative glucose control in patients undergoing coronary artery bypass graft surgery: GLUCO-CABG trial. Diabetes Care. 2015;38:1665-72.

29. Krinsley JS, Preiser J-C, Hirsch IB. Safety and efficacy of personalized glycemic control in critically ill patients: a 2-year before and after intervention trial. Endocr Pract. 2017;23:318-30.
30. Chao W-C, Tseng C-H, Wu C-L, Shih S-J, Yi C-Y, Chan M-C. Higher glycemic variability within the first day of ICU admission is associated with increased 30-day mortality in ICU patients with sepsis. Ann Intensive Care. 2020;10:17.

31. Ceriello A, Standl E, Catrinoiu D, et al. Issues of cardiovascular risk management in people with diabetes in the COVID-19 era. Diabetes Care. 2020;43(7):1427-32.

32. American Diabetes Association. 15. Diabetes Care in the Hospital: standards of medical care in diabetes-2020. Diabetes Care. 2020;43:S193-202.

33. Pasquel FJ, Umpierrez GE. Individualizing inpatient diabetes management during the coronavirus disease 2019 pandemic. J Diabetes Sci Technol. 2020;14(4):705-7.

34. Hamdy O, Gabbay RA. Early observation and mitigation of challenges in diabetes management of COVID-19 patients in critical care units. Diabetes Care. 2020;43(8):e81-e82.

35. Moghissi ES, Korytkowski MT, DiNardo M, et al. American Association of Clinical Endocrinologists and American Diabetes Association consensus statement on inpatient glycemic control. Diabetes Care. 2009;32:1119-31.

36. Pérez Pérez A, Conthe Gutiérrez P, Aguilar Diosdado $\mathrm{M}$, et al. Hospital management of hyperglycemia. Med Clin. 2009;132:465-75.

37. Avanzini F, Marelli G, Donzelli W, et al. Transition from intravenous to subcutaneous insulin: effectiveness and safety of a standardized protocol and predictors of outcome in patients with acute coronary syndrome. Diabetes Care. 2011;34:1445-50.

38. Ramos A, Zapata L, Vera P, Betbese AJ, Pérez A. Transition from intravenous insulin to subcutaneous long-acting insulin in critical care patients on enteral or parenteral nutrition. Endocrinol Diabetes Nutr. 2017;64:552-6.

39. Umpierrez GE, Hellman R, Korytkowski MT, et al. Management of hyperglycemia in hospitalized patients in non-critical care setting: an Endocrine Society clinical practice guideline. J Clin Endocrinol Metab. 2012;97:16-38.

40. Umpierrez GE, Gianchandani R, Smiley D, et al. Safety and efficacy of sitagliptin therapy for the inpatient management of general medicine and surgery patients with type 2 diabetes: a pilot, randomized, controlled study. Diabetes Care. 2013;36: 3430-5.

41. Pasquel FJ, Gianchandani R, Rubin DJ, et al. Efficacy of sitagliptin for the hospital management of 
general medicine and surgery patients with type 2 diabetes (Sita-Hospital): a multicentre, prospective, open-label, non-inferiority randomised trial. Lancet Diabetes Endocrinol. 2017;5:125-33.

42. Vellanki P, Rasouli N, Baldwin D, et al. Glycaemic efficacy and safety of linagliptin compared to a basal-bolus insulin regimen in patients with type 2 diabetes undergoing non-cardiac surgery: a multicentre randomized clinical trial. Diabetes Obes Metab. 2019;21:837-43.

43. Umpierrez GE, Cardona S, Chachkhiani D, et al. A randomized controlled study comparing a DPP4 inhibitor (linagliptin) and basal insulin (glargine) in patients with type 2 diabetes in long-term care and skilled nursing facilities: linagliptin-LTC trial. J Am Med Dir Assoc. 2018;19(399-404):e3.

44. Pérez-Belmonte LM, Osuna-Sánchez J, MillánGómez M, et al. Glycaemic efficacy and safety of linagliptin for the management of non-cardiac surgery patients with type 2 diabetes in a real-world setting: Lina-Surg study. Ann Med. 2019;51:252-61.

45. Iacobellis G. COVID-19 and diabetes: can DPP4 inhibition play a role? Diabetes Res Clin Pract. 2020;162:108125.

46. Cariou B, Hadjadj S, Wargny M, et al. Phenotypic characteristics and prognosis of inpatients with COVID-19 and diabetes: the CORONADO study. Diabetologia. 2020. https://doi.org/10.1007/ s00125-020-05180-X.

47. Fadini GP, Morieri ML, Longato E, et al. Exposure to dipeptidyl-peptidase- 4 inhibitors and COVID-19 among people with type 2 diabetes: a case-control study. Diabetes Obes Metab. 2020;22:1946-50.

48. Fayfman M, Galindo RJ, Rubin DJ, et al. A randomized controlled trial on the safety and efficacy of exenatide therapy for the inpatient management of general medicine and surgery patients with type 2 diabetes. Diabetes Care. 2019;42:450-6.

49. Bornstein SR, Rubino F, Khunti K, et al. Practical recommendations for the management of diabetes in patients with COVID-19. Lancet Diabetes Endocrinol. 2020;8:546-50.

50. Bossi AC, Forloni F, Colombelli PL. Lack of efficacy of SGLT2-i in severe pneumonia related to novel coronavirus (nCoV) infection: no little help from our friends. Diabetes Ther. 2020. https://doi.org/10. 1007/s13300-020-00844-8.

51. Cure E, Cumhur CM. Can dapagliflozin have a protective effect against COVID-19 infection? A hypothesis. Diabetes Metab Syndr. 2020;14:405-6.
52. Umpierrez GE, Smiley D, Zisman A, et al. Randomized study of basal-bolus insulin therapy in the inpatient management of patients with type 2 diabetes (RABBIT 2 trial). Diabetes Care. 2007;30: 2181-6.

53. Bellido V, Suarez L, Rodriguez MG, et al. Comparison of basal-bolus and premixed insulin regimens in hospitalized patients with type 2 diabetes. Diabetes Care. 2015;38:2211-6.

54. Umpierrez GE, Smiley D, Hermayer K, et al. Randomized study comparing a basal-bolus with a basal plus correction insulin regimen for the hospital management of medical and surgical patients with type 2 diabetes: basal plus trial. Diabetes Care. 2013;36:2169-74.

55. Bueno E, Benitez A, Rufinelli JV, et al. Basal-bolus regimen with insulin analogues versus human insulin in medical patients with type 2 diabetes: a randomized controlled trial in Latin America. Endocr Pract. 2015;21:807-13.

56. Pasquel FJ, Lansang MC, Khowaja A, et al. A randomized controlled trial comparing glargine U300 and glargine U100 for the inpatient management of medicine and surgery patients with type 2 diabetes: glargine U300 hospital trial. Diabetes Care. 2020;43:1242-8.

57. Pérez A, Carrasco-Sánchez FJ, González C, et al. Efficacy and safety of insulin glargine $300 \mathrm{U} / \mathrm{ml}$ (Gla-300) during hospitalization and therapy intensification at discharge in patients with insufficiently controlled type 2 diabetes: results of the phase IV COBALTA trial. BMJ Open Diabetes Res Care. 2020;8(1):e001518.

58. Mehta P, McAuley DF, Brown M, et al. COVID-19: consider cytokine storm syndromes and immunosuppression. Lancet. 2020;395:1033-4.

59. Shehav-Zaltzman G, Segal G, Konvalina N, Tirosh A. Remote glucose monitoring of hospitalized, quarantined patients with diabetes and COVID-19. Diabetes Care. 2020;43(7):e75-e76.

60. FDA. FAQs on home-use blood glucose meters utilized within hospitals during the COVID-19 pandemic. https://www.fda.gov/medical-devices/ blood-glucose-monitoring-devices/faqs-home-useblood-glucose-meters-utilized-within-hospitalsduring-covid-19-pandemic. Accessed 7 Sept 2020.

61. Wallia A, Umpierrez GE, Rushakoff RJ, et al. Consensus statement on inpatient use of continuous glucose monitoring. J Diabetes Sci Technol. 2017;11:1036-44. 
62. Levitt DL, Silver KD, Spanakis EK. Inpatient continuous glucose monitoring and glycemic outcomes. J Diabetes Sci Technol. 2017;11:1028-35.

63. Nair BG, Dellinger EP, Flum DR, Rooke GA, Hirsch IB. A pilot study of the feasibility and accuracy of inpatient continuous glucose monitoring. Diabetes Care. 2020;43(11):e168-e169.

64. Welsh JB, Hu G, Walker TC, Sharma N, Cherñavvsky D. Glucose monitoring and diabetes management in the time of coronavirus disease 2019. J Diabetes Sci Technol. 2020;14(4):809-10.

65. Abbott. FreeStyle Libre: diabetes care during COVID-19. 2020. https://www.abbott.com/ corpnewsroom/product-and-innovation/freestylelibre-diabetes-care-during-covid-19.html. Accessed 7 Sept 2020.

66. Dexcom. Fact Sheet for healthcare providers: use of dexcom continuous glucose monitoring systems during the COVID-19 pandemic. 2020. https:// www.dexcom.com/hospitalfacts. Accessed 7 Sept 2020.

67. Preiser J-C, Chase JG, Hovorka R, et al. Glucose control in the ICU: a continuing story. J Diabetes Sci Technol. 2016;10:1372-81.

68. Basu A, Slama MQ, Nicholson WT, et al. Continuous glucose monitor interference with commonly prescribed medications: a pilot study. J Diabetes Sci Technol. 2017;11:936-41.

69. Umpierrez GE, Klonoff DC. Diabetes technology update: use of insulin pumps and continuous glucose monitoring in the hospital. Diabetes Care. 2018;41:1579-89.

70. Bellido V, Pérez A. Consequences of COVID-19 on people with diabetes. Endocrinol Diabetes Nutr. 2020;67(6):355-6. 